\title{
Nucleolar and spindle-associated protein 1 promotes non-small cell lung cancer progression and serves as an effector of myocyte enhancer factor 2D
}

\author{
BO LING ${ }^{1,2}$, PENGYA WEI ${ }^{1}$, JUAN XIAO ${ }^{3}$, BINGKUI CEN $^{1}$, HONG WEI $^{1}$, XUEPING FENG $^{1}$, GUANGBIN YE $^{1,2}$, \\ SONGBO LI ${ }^{1}$, ZHONGWEI ZHANG ${ }^{1,2}$, WEI LIANG ${ }^{1,2}$, SUOYI HUANG ${ }^{1,2}$ and WEI HUANG ${ }^{4}$ \\ ${ }^{1}$ College of Pharmacy, ${ }^{2}$ Key Laboratory of Guangxi's College for The Study of Characteristic Medicine \\ in Youjiang River Basin, Youjiang Medical University for Nationalities, Baise, Guangxi 533000; \\ ${ }^{3}$ Laboratory of Hepatobiliary and Pancreatic Surgery, Affiliated Hospital of Guilin Medical University, Guilin, \\ Guangxi 541001; ${ }^{4}$ Department of Thoracic Surgery, Chongqing General Hospital, Chongqing 400013, P.R. China
}

Received October 19, 2019; Accepted October 15, 2020

DOI: $10.3892 /$ or.2020.7918

\begin{abstract}
As a potential oncogene, nucleolar and spindle-associated protein 1 (NUSAP1) is involved in the regulation of tumor cell proliferation, metastasis and drug resistance. However, the role of NUSAP1 in non-small cell lung cancer (NSCLC) remains unclear. The present study aimed to investigate the biological function and underlying molecular mechanisms of NUSAP1 in NSCLC. NUSAP1 expression was measured in NSCLC tissues and cell lines via immunohistochemistry and western blotting, respectively. NSCLC cell lines stably inhibiting NUSAP1 were established to investigate its effects on cell proliferation, colony formation and invasion, and on in vivo tumorigenicity. Additionally, the upstream and downstream mechanisms of NUSAP1 in regulating NSCLC progression were investigated. The results indicated that NUSAP1 expression was upregulated in NSCLC tissues and cell lines. High NUSAP1 expression was associated with tumor size, TNM stage, lymph node metastasis and poor patient survival, whereas knockdown of NUSAP1 inhibited NSCLC cell proliferation, colony formation and invasion. Furthermore, downregulation of NUSAP1 decreased the growth of NSCLC xenografts in vivo. In addition, myocyte
\end{abstract}

Correspondence to: Professor Suoyi Huang, Key Laboratory of Guangxi's College for The Study of Characteristic Medicine in Youjiang River Basin, Youjiang Medical University for Nationalities, 98 Chengxiang Road, Baise, Guangxi 533000, P.R. China E-mail: huangsuoyi@163.com

Dr Wei Huang, Department of Thoracic Surgery, Chongqing General Hospital, 312 Zhongshan Road, Yuzhong, Chongqing 400013, P.R. China

E-mail: 13060252697@163.com

Key words: nucleolar and spindle-associated protein 1, myocyte enhancer factor 2D, non-small cell lung cancer, proliferation, migration enhancer factor 2D (MEF2D) directly targeted the NUSAP1 promoter, thereby enhancing the mRNA and protein expression levels of NUSAP1. Moreover, the results demonstrated that MEF2D expression was upregulated in NSCLC tissues and was positively correlated with NUSAP1 expression. MEF2D-knockdown decreased NSCLC cell proliferation, colony formation and invasion. NUSAP1 upregulation reversed the effects of MEF2D-knockdown on NSCLC progression. Furthermore, it was observed that MEF2D-knockdown inhibited the accumulation and nuclear translocation of $\beta$-catenin, thereby repressing the activation of the $\mathrm{Wnt} / \beta$-catenin signaling pathway in NSCLC cells, whereas NUSAP1 upregulation rescued the effects of MEF2D-knockdown on the activation of the Wnt/ $\beta$-catenin signaling pathway. In conclusion, the findings of the present study indicated that the MEF2D/NUSAP1 signaling pathway promoted NSCLC progression by inducing the activation of $\mathrm{Wnt} / \beta$-catenin signaling, and this novel mechanism may represent a potential treatment target for patients with NSCLC.

\section{Introduction}

Lung cancer is the leading cause of cancer-associated mortality globally, with a 5-year survival rate $<20 \%$ (1). Non-small cell lung cancer (NSCLC) accounts for $\sim 85 \%$ of all lung cancer cases and it is usually diagnosed at an advanced stage (2). Molecularly targeted drugs, including gefitinib and erlotinib, have been approved for clinical treatment of NSCLC and have improved the survival and quality of life of patients with NSCLC (3). However, the problems of recurrence, metastasis and drug resistance have not been resolved, resulting in poor outcomes in patients (4). Therefore, it is crucial to identify new molecular targets for clinical diagnosis and therapy of NSCLC.

Nucleolar and spindle-associated protein 1 (NUSAP1) is a microtubule-binding protein that serves an important role in mitotic progression, spindle assembly and stability $(5,6)$. High NUSAP1 expression has been identified in various types of cancer, such as in metastatic prostate cancer (7-14). In addition, high NUSAP1 expression has been associated with worse 
clinical outcomes in several types of tumor, including estrogen receptor-positive breast cancer, prostate cancer, cervical carcinoma and hepatocellular carcinoma (HCC) (11-14). Moreover, NUSAP1 expression is upregulated in cervical carcinoma and contributes to metastasis by enhancing cancer stem cell traits and epithelial-to-mesenchymal transition (EMT) (13). In HCC, NUSAP1-knockdown inhibits cell proliferation and increases apoptotic cell death (14). These findings suggest that NUSAP1 is involved in the initiation and progression of human cancer. Notably, Bidkhori et al (15) reported that NUSAP1 expression is upregulated in lung cancer, and $\mathrm{Xu}$ et al (16) demonstrated that NUSAP1-knockdown inhibits NSCLC cell proliferation, migration and invasion. However, the role and mechanism of action of NUSAP1 in NSCLC has not been fully elucidated.

The present study aimed to analyze NUSAP1 expression in NSCLC tissues and to analyze the association between its expression and clinicopathological characteristics in patients with NSCLC. Additionally, the present study aimed to investigate the biological function and underlying molecular mechanisms of NUSAP1 in NSCLC. NSCLC cell lines stably inhibiting NUSAP1 were established to investigate its effects on cell proliferation, colony formation and invasion, and on in vivo tumorigenicity. Furthermore, the upstream and downstream mechanisms of NUSAP1 in regulating NSCLC progression were investigated.

\section{Materials and methods}

Patients and tissue specimens. A total of 115 NSCLC tissue specimens were collected from patients who underwent surgical resection at Chongqing General Hospital (Chongqing, China) between February 2009 and May 2011. The age of the patients ranged between 37 and 65 years, with a median age of 52 years. Among the 115 tissues, 35 pairs of human NSCLC and adjacent normal tissues ( $2 \mathrm{~cm}$ from the tumor) were selected from these patients and stored at $-80^{\circ} \mathrm{C}$. All patients provided written informed consent, and the study protocol was approved by the Ethics Committee of Chongqing General Hospital (approval no. 2015082104). None of the patients had received radiotherapy or neoadjuvant chemotherapy prior to surgery. All the samples used were examined, and diagnosis was confirmed by two pathologists. Clinicopathological data, including age, sex, smoking status, tumor size, histological type, TNM stage (17) and lymph node metastasis, were available for the patients diagnosed with NSCLC. The patient samples were categorized into two groups according to the median NUSAP1 expression (high vs. low expression). The clinical outcomes of patients with NSCLC were recorded until January 2018. The clinical information of these patients is summarized in Table I.

Immunohistochemistry (IHC). IHC examination of NUSAP1 expression was performed as described previously (18). NSCLC tissues were fixed in $10 \%(\mathrm{v} / \mathrm{v})$ formaldehyde at room temperature for $24 \mathrm{~h}$, embedded in paraffin and cut into $4-\mu$ m-thick sections. Subsequently, the sections were dewaxed using xylene. Following rehydration in a descending alcohol series $(100,95,80$ and $70 \%$ ethanol) at room temperature, antigen retrieval was performed by microwave treatment with citrate buffer ( $\mathrm{pH} 6.0$ ) for $15 \mathrm{~min}$ at $750 \mathrm{~W}$, followed by the addition of $10 \%$ goat non-immune serum (Boster Biological Technology) for blocking at room temperature for $1 \mathrm{~h}$. The sections were then incubated with a rabbit anti-NUSAP1 polyclonal antibody (1:400; cat. no. 12024-1-AP; ProteinTech Group, Inc.) at $4^{\circ} \mathrm{C}$ overnight, followed by incubation with a biotin-labeled secondary antibody (1:500; cat. no. ab7089; Abcam) at $37^{\circ} \mathrm{C}$ for $30 \mathrm{~min}$. Finally, freshly prepared 3,3'-diaminobenzidine from a DAB Substrate kit (Abcam) was added for color development.

Images were obtained using a light microscope (magnification, $\mathrm{x} 100$ ), and NUSAP1 expression was scored according to the percentage of positive cells and the staining intensity (19). The percentage of positive cells was scored as follows: 0,$0 ; 1$, $<5 ; 2,5-50$; and $3,>50 \%$ positive cells. The staining intensity was determined in 10-20 areas at $\mathrm{x} 400$ magnification by visual assessment, regardless of the percentage of staining, and the intensity of staining was classified as follows: 0 , negative (no positive cells); 1 , weak; 2 , moderate; and 3, strong (20,21). The final staining scores of NUSAP1 expression in NSCLC tissues were calculated by multiplying the staining intensity score and the percentage score. If the final score was $\geq 4$, the protein expression was considered as high, whereas if the score was $\leq 3$, the protein expression was considered as low.

Cell culture. Four NSCLC cell lines (A549, H1299, HCC827 and H358) and one normal human lung epithelial cell line (BEAS-2B) were obtained from the Cell Bank of Type Culture Collection of the Chinese Academy of Sciences. H1299, HCC827 and H358 cells were cultured in RPMI-1640 medium supplemented with 10\% FBS (Gibco; Thermo Fisher Scientific, Inc.) and $1 \%$ penicillin/streptomycin (Invitrogen; Thermo Fisher Scientific, Inc.), and A549 cells were cultured in F12K medium (Sigma-Aldrich; Merck KGaA) supplemented with $10 \%$ FBS. BEAS-2B cells were cultured in medium from a Bronchial Epithelial Cell Growth Medium Bullet kit (Clonetics Corporation). All cell lines were cultured in an incubator with $5 \% \mathrm{CO}_{2}$ at $37^{\circ} \mathrm{C}$.

Cell transfection. Short hairpin RNA (shRNA) fragments of NUSAP1, MEF2D, zinc finger E-box binding homeobox 1 (ZEB1) and E2F transcription factor 1 (E2F1) were synthesized and constructed into the U6-shRNA-CMV-puromycin vector by SunBio, Inc. The shRNA sequences are listed in Table II, including a universal non-targeting control used as the negative control (NC). Cell transfection was performed using Lipofectamine ${ }^{\circledR} 2000$ (Invitrogen; Thermo Fisher Scientific, Inc.) according to the manufacturer's instructions. H1299 and

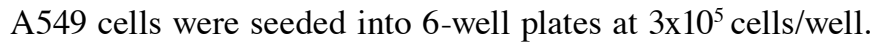
When cells reached 70-90\% confluence, $2.5 \mu \mathrm{g}$ NUSAP1 shRNA, MEF2D shRNA or NC with $8 \mu$ l Lipofectamine 2000 in $250 \mu$ l Opti-MEM ${ }^{\circledR}$ (Gibco; Thermo Fisher Scientific, Inc.) was added into each well. A549 cells were seeded into 6-well plates at $3 \times 10^{5}$ cells/well. When cells reached $70-90 \%$ confluence, $2.5 \mu \mathrm{g}$ ZEB1 shRNA, E2F1 shRNA or NC with $8 \mu \mathrm{l}$ Lipofectamine 2000 in $250 \mu \mathrm{l}$ Opti-MEM was added into each well. After $72 \mathrm{~h}$ of transfection at $37^{\circ} \mathrm{C}, \mathrm{H} 1299$ and A549 cells were selected with 2 or $1 \mu \mathrm{g} / \mathrm{ml}$ puromycin, respectively, for 14 days. Finally, a fluorescence microscope (MicroPublisher ${ }^{\mathrm{TM}}$ 3.3RTV; Olympus Corporation; magnification, x100) was used to evaluate transfection efficiency. The transfection efficiency 
Table I. Associations between NUSAP1 expression and clinicopathological characteristics of patients with non-small cell lung cancer.

\begin{tabular}{|c|c|c|c|}
\hline \multirow[b]{2}{*}{ Clinical factors } & \multicolumn{2}{|c|}{$\begin{array}{l}\text { NUSAP1 } \\
\text { expression }\end{array}$} & \multirow[b]{2}{*}{ P-value } \\
\hline & $\begin{array}{c}\text { Low } \\
(n=51)\end{array}$ & $\begin{array}{l}\text { High } \\
(n=64)\end{array}$ & \\
\hline Age, years & & & 0.454 \\
\hline$<60$ & 30 & 42 & \\
\hline$\geq 60$ & 21 & 22 & \\
\hline Sex & & & 0.849 \\
\hline Male & 23 & 30 & \\
\hline Female & 28 & 34 & \\
\hline Smoking status & & & 0.573 \\
\hline Never smoke & 25 & 28 & \\
\hline Smoke & 26 & 36 & \\
\hline Tumor size, cm & & & $0.005^{\mathrm{a}}$ \\
\hline$<3$ & 35 & 27 & \\
\hline$\geq 3$ & 16 & 37 & \\
\hline Histological type & & & 0.187 \\
\hline Squamous cell carcinoma & 20 & 33 & \\
\hline Adenocarcinoma & 31 & 31 & \\
\hline TNM stage & & & $0.004^{\mathrm{a}}$ \\
\hline $\mathrm{I}+\mathrm{II}$ & 33 & 24 & \\
\hline III+IV & 18 & 40 & \\
\hline Lymph node metastasis & & & $0.026^{\mathrm{b}}$ \\
\hline No & 36 & 32 & \\
\hline Yes & 15 & 32 & \\
\hline
\end{tabular}

${ }^{\mathrm{a}} \mathrm{P}<0.01 ;{ }^{\mathrm{b}} \mathrm{P}<0.05$.

was calculated using the percentage of RFP-positive cells in total cells. Three images at x100 magnification per sample were used for quantification. The mean percentage was obtained from three images, and three samples were used per group. For NUSAP1 and MEF2D overexpression, the coding sequences of NUSAP1 and MEF2D were subcloned into a pcDNA3.1 vector carrying a neomycin resistance gene by SunBio, Inc. An empty vector was used as the NC. Cell transfection was performed using Lipofectamine 2000 according to the manufacturer's instructions. HCC827 cells were seeded into 6 -well plates at $3 \times 10^{5}$ cells/well. When cells reached $70-90 \%$ confluence, $2.5 \mu \mathrm{g}$ pcDNA3.1 or MEF2D overexpression vectors with $8 \mu \mathrm{l}$ Lipofectamine 2000 in $250 \mu \mathrm{l}$ Opti-MEM was added into each well. H1299 and A549 cells pretreated with NC and MEF2D shRNA were seeded into 6-well plates at $3 \times 10^{5}$ cells/well. When cells reached $70-90 \%$ confluence, $2.5 \mu \mathrm{g}$ pcDNA3.1 or NUSAP1 overexpression vectors with $8 \mu \mathrm{l}$ Lipofectamine 2000 in $250 \mu \mathrm{l}$ Opti-MEM was added into each well. After $72 \mathrm{~h}$ of transfection at $37^{\circ} \mathrm{C}, \mathrm{H} 1299$, A549 and HCC827 cells were selected with 200,500 or $400 \mu \mathrm{g} / \mathrm{ml}$ G418, respectively, for 14 days. Finally, a fluorescence microscope (MicroPublisher ${ }^{\mathrm{TM}}$ 3.3RTV; Olympus Corporation; magnification, $\mathrm{x} 100$ ) was used to evaluate transfection efficiency. The transfection efficiency was calculated using the percentage of EGFP-positive cells in total cells. Three images at x100 magnification per sample were used for quantification. The mean percentage was obtained from three images, and three samples were used per group.

Western blotting. Western blotting was performed as described previously (19). Four NSCLC cell lines (A549, H1299, HCC827 and H358) and one normal human lung epithelial cell line (BEAS-2B) after transfection were harvested and lysed using RIPA lysis and extraction buffer (cat. no. 89900; Thermo Fisher Scientific, Inc.). The Nuclear and Cytoplasmic Extraction Reagent kit (cat. no. 78835; Thermo Fisher Scientific, Inc.) was used to isolate the nuclear and cytoplasmic fractions according to the manufacturer's instructions. The BCA method was used to determine the protein concentration. Equal amounts of total protein (30 $\mu \mathrm{g} /$ lane) from each cell lysate were subjected to $10 \%$ SDS-PAGE and transferred onto PVDF membranes. The membranes were incubated with $5 \%$ skimmed milk at room temperature for $1 \mathrm{~h}$. Subsequently, the membranes were incubated overnight at $4^{\circ} \mathrm{C}$ with the following primary antibodies: Rabbit anti-NUSAP1 polyclonal antibody (1:100; cat. no. 12024-1-AP; ProteinTech Group, Inc.), rabbit anti-MEF2D polyclonal antibody (1:800; cat. no. ab32845; Abcam), mouse anti-GAPDH monoclonal antibody (1:20,000; cat. no. 60004-1-Ig; ProteinTech Group, Inc.), rabbit anti- $\beta$-catenin monoclonal antibody $(1: 9,000$; cat. no. ab32572; Abcam), rabbit anti-c-Myc monoclonal antibody (1:600; cat. no. ab32072; Abcam), mouse anti-cyclin D1 monoclonal antibody (1:6,000; cat. no. 60186-1-Ig; ProteinTech Group, Inc.), rabbit anti-matrix metallopeptidase (MMP7) polyclonal antibody (1:500; cat. no. 10374-2-AP; ProteinTech Group, Inc.), rabbit anti-histone H3 polyclonal antibody (1:4,000; cat. no. 17168-1-AP; ProteinTech Group, Inc.), rabbit anti-ZEB1 polyclonal antibody (1:1,000; cat. no. 21544-1-AP; ProteinTech Group, Inc.) and rabbit anti-E2F1 polyclonal antibody (1:800; cat. no. 12171-1-AP; ProteinTech Group, Inc.). After washing with TBS-Tween (0.1\% Tween-20), the membranes were incubated with HRP-conjugated Affinipure goat anti-rabbit (1:10,000; cat. no. SA00001-2; ProteinTech Group, Inc.) or goat anti-mouse (1:8,000; cat. no. SA00001-1; ProteinTech Group, Inc.) at room temperature for $1 \mathrm{~h}$. Finally, the Pierce ECL Western Blotting Substrate (cat. no. 32106; Thermo Fisher Scientific, Inc.) was used for visualization. GAPDH and Histone H3 were used as the internal controls. Image J software (version 1.52q; National Institutes of Health) was used for densitometric analysis, and grey values were normalized to GAPDH or Histone H3, and expressed as relative densities.

Reverse transcription-quantitative PCR (RT-qPCR) analysis. Total RNA was extracted from H1299, A549 and HCC827 cells after transfection using TRIzol ${ }^{\circledR}$ reagent (cat. no. 15596026; Invitrogen; Thermo Fisher Scientific, Inc.) according to the manufacturer's instructions. Subsequently, cDNA was synthesized at $42^{\circ} \mathrm{C}$ for $1 \mathrm{~h}$ and $70^{\circ} \mathrm{C}$ for 10 min using a PrimeScript RT reagent kit (cat. no. RR047A; Takara Biotechnology Co., Ltd.). qPCR analysis was performed on an MxPro Mx3000P Sequence Detection system (Stratagene; Agilent 
Table II. Sequences of shRNAs and primers used for reverse transcription-quantitative PCR.

\begin{tabular}{ll}
\hline Name & \multicolumn{1}{c}{ Sequences } \\
\hline NUSAP1 forward & 5'-TTCTGCTGCTGTTATTAC-3' \\
NUSAP1 reverse & 5'-GTGTGGTTCATAGTTGAG-3' \\
MEF2D forward & 5'-CAGCAGCCAGCACTACAGAG-3' \\
MEF2D reverse & 5'-GGCAGGGATGACCTTGTTTA-3' \\
GAPDH forward & 5'-AGAAGGCTGGGGCTCATTTG-3' \\
GAPDH reverse & 5'-AGGGGCCATCCACAGTCTTC-3' \\
NUSAP1 shRNA sense & 5'-CCGGCCTCAGGTAACAGAGATTCAACTCGAGTTGAATCTCTGTTACCTGAGGTTTTTTG-3' \\
NUSAP1 shRNA antisense & 5'-AATTCAAAAAACCTCAGGTAACAGAGATTCAACTCGAGTTGAATCTCTGTTACCTGAGG-3' \\
MEF2D shRNA sense & 5'-CCGGCAACAGCCTAAACAAGGTCATCTCGAGATGACCTTGTTTAGGCTGTTGTTTTTG-3' \\
MEF2D shRNA antisense & 5'-AATTCAAAAAACAACAGCCTAAACAAGGTCACTCGAGATGACCTTGTTTAGGCTGTTG-3' \\
ZEB1 shRNA sense & 5'-CCGGTGTCTCCCATAAGTATCAATTCTCGAGAATTGATACTTATGGGAGACATTTTTTG-3' \\
ZEB1 shRNA antisense & 5'-AATTCAAAAAATGTCTCCCATAAGTATCAATTCTCGAGAATTGATACTTATGGGAGACA-3' \\
E2F1 shRNA sense & 5'-CCGGCAGGATGGATATGAGATGGGACTCGAGTCCCATCTCATATCCATCCTGTTTTTG-3' \\
E2F1 shRNA antisense & 5'-AATTCAAAAAACAGGATGGATATGAGATGGGACTCGAGTCCCATCTCATATCCATCCTG-3' \\
shNC sense & 5'-CCGGTTCTCCGAACGTGTCACGTTTCAAGAGAACGTGACACGTTCGGAGAATTTTG-3' \\
shNC antisense & 5'-AATTCAAAAATTCTCCGAACGTGTCACGTTCTCTTGAAACGTGACACGTTCGGAGAA-3' \\
\hline
\end{tabular}

shRNA, short hairpin RNA; NC, negative control; NUSAP1, nucleolar and spindle-associated protein 1; MEF2D, myocyte enhancer factor 2D; ZEB1, zinc finger E-box binding homeobox 1; E2F1, E2F transcription factor 1 .

Technologies, Inc.) using a SYBR Prime Script RT-PCR kit (cat. no. RR066A; Takara Biotechnology Co., Ltd.). The thermocycling conditions for PCR were as follows: Pre-incubation at $95^{\circ} \mathrm{C}$ for $15 \mathrm{sec}$, followed by 45 cycles at $95^{\circ} \mathrm{C}$ for $5 \mathrm{sec}$ and $60^{\circ} \mathrm{C}$ for $30 \mathrm{sec}$. GAPDH was used as the internal control, and the $2^{-\Delta \Delta \mathrm{Cq}}$ analysis method was used to evaluate NUSAP1 expression (22). The primer sequences are listed in Table II.

Cell Counting Kit-8 (CCK-8) assay. CCK-8 assay (cat. no. 96992; Sigma-Aldrich; Merck KGaA) was used to determine NSCLC cell proliferation. H1299 and A549 cells were seeded in 96-well plates at a density of $1 \times 10^{4}$ cells/well. Subsequently, $10 \mu 1$ CCK-8 solution was added to each well of the plate after $0,1,2,3,4$ or 5 days, and further incubated for $2 \mathrm{~h}$ at $37^{\circ} \mathrm{C}$. The absorbance of each well of the plate was measured at $450 \mathrm{~nm}$ using a microculture plate reader (BioTek Instruments, Inc.).

Transwell assay. The invasion ability of NSCLC cells was analyzed using a 24-well Transwell chamber with $8.0-\mu \mathrm{m}$ pore membranes (cat. no. 3577; Costar; Corning, Inc.). Matrigel ${ }^{\circledR}$ (100 $\mu$ l; cat. no. 356234; BD Biosciences) was added to the upper chambers of the Transwell system for $15 \mathrm{~min}$ at $37^{\circ} \mathrm{C}$. Subsequently, $1 \times 10^{5} \mathrm{H} 1299$ and A549 cells in $100 \mu 1$ serum-free medium (RPMI-1640 or F12K medium) were seeded into the upper Transwell chambers. The bottom chambers were filled with $500 \mu \mathrm{l}$ RPMI-1640 or F12K medium supplemented with $10 \% \mathrm{FBS}$. After culturing for $48 \mathrm{~h}$ at $37^{\circ} \mathrm{C}$, the cells in the upper surface of the filter were removed with a cotton swab, and the cells on the lower surface of the filter were fixed with $4 \%$ paraformaldehyde at room temperature for $15 \mathrm{~min}$ and stained with $0.1 \%$ crystal violet for $5 \mathrm{~min}$ at room temperature. Finally, the tumor cells were counted under a light microscope (IX71; Olympus Corporation) in five random fields at a magnification of $\times 200$.

Colony formation assay. To analyze the cell colony-forming ability, H1299 and A549 cells were seeded at a concentration of 500 cells/well, and cultured for 2 weeks at $37^{\circ} \mathrm{C}$. Subsequently, the cells were fixed with $4 \%$ paraformaldehyde at room temperature for $15 \mathrm{~min}$ and stained with $0.1 \%$ crystal violet for $20 \mathrm{~min}$ at room temperature. The number of colonies containing $>50$ cells was counted under a light microscope (IX71; Olympus Corporation; magnification, x400).

Xenograft model in nude mice. A total of 8 female BALB/c nude mice (age, 5 weeks; weight, 14-19 g) were purchased from the Shanghai SLAC Laboratory Animal Co., Ltd., and kept in an animal room at a constant temperature of $23 \pm 1^{\circ} \mathrm{C}$ and humidity of $50 \pm 1 \%$ with a 12 -h artificial light/dark cycle and free access to food and water. Animal health and behavior were monitored every day. All animal experiments were approved by the Animal Care Committee of Youjiang Medical University for Nationalities (approval no. 2018092703; Guangxi, China) and complied with the recommendations of the Chinese Guidelines for the Care and Use of Laboratory Animals (23). Mice were anesthetized with 3\% isoflurane. A549 cells $\left(1 \times 10^{7}\right.$ cells in $100 \mu \mathrm{l}$ PBS) stably expressing NUSAP1 shRNA (NUSAP1 RNAi) or a universal shNC were injected subcutaneously into the flanks of BALB/c nude mice (four in each group). The tumor volume was measured weekly. If the tumor burden was $>10 \%$ of the body weight in each 
mouse, or tumors became ulcerated, infected or necrotic, or the longest tumor diameter was $>2 \mathrm{~cm}$, euthanasia was used to halt the experiment. At 5 weeks after injection, all mice were euthanized by intraperitoneal injection of pentobarbital sodium (200 mg/kg; ChemicalBook, Inc.), and the animal death was verified through a combination of criteria, including lack of pulse, breathing, corneal reflex, response to firm toe pinch, graying of the mucous membranes and rigor mortis. After euthanasia, the tumors were resected and the tumor volume was calculated as follows: Volume $=($ length $\mathrm{x}$ width $\mathrm{x}$ width) $/ 2$. None of the mice presented multiple tumors before euthanasia.

Luciferase assay. For luciferase reporter assays, the NUSAP1 promoter containing the MEF2D-binding site (from 1,519 to $1,508 \mathrm{bp}$ ) was amplified from A549 cells by PCR and cloned into the pGL3-Basic luciferase reporter vector by SunBio, Inc. A mutated NUSAP1 promoter (pNUSAP1-mut) with deletion of the MEF2D-binding site was also generated by SunBio, Inc. H1299 and A549 cells were co-transfected with a universal shNC or MEF2D shRNA (MEF2D RNAi) and wild-type NUSAP1 luciferase reporter vector (pNUSAP1-luc). In addition, HCC827 cells were co-transfected with a MEF2D pcDNA3.1 vector (MEF2D) or a pcDNA3.1 control vector (pcDNA3.1) and pNUSAP1-luc or pNUSAP1-mut. After $48 \mathrm{~h}$ of transfection using Lipofectamine 2000 at $37^{\circ} \mathrm{C}$, the cells were lysed in lysis buffer, and the luciferase activity was determined using a Dual-luciferase reporter assay system (cat. no. E1910; Promega Corporation) according to the manufacturer's instructions. The firefly luciferase activity was normalized to the Renilla luciferase activity.

Bioinformatics and data analysis. The expression levels of NUSAP1 in NSCLC tissues were investigated using the Gene Expression database of Normal and Tumor tissues (GENT; http://medical-genome.kribb.re.kr/GENT/) (24). NUSAP1 mRNA and survival data in NSCLC were obtained from Kaplan-Meier plotter (http://kmplot.com/analysis/). The promoter region of NUSAP1 was scanned for known transcription factors using the JASPAR database (http://jaspar. genereg.net/collection/core/) and GeneCard (https:/www. genecards.org/).

Statistical analysis. All data were analyzed using SPSS 20.0 (IBM Corp.) and are presented as the mean \pm SD from three independent experiments. The correlation between NUSAP1 and MEF2D expression in tissue specimens was analyzed using Pearson's correlation. The expression levels of NUSAP1 and MEF2D mRNA in paired tissue specimens was assessed using paired Student's t-tests. In functional experiments, the differences between two groups were assessed using unpaired Student's t-tests, while one-way ANOVA followed by Tukey's post hoc test was conducted for comparisons of multiple groups. The associations between NUSAP1 and the clinicopathological characteristics of patients with NSCLC were analyzed using Pearson's $\chi^{2}$ test. The Kaplan-Meier method was used to construct survival curves, and the significance was analyzed using the log-rank test. Multivariate analysis was performed using the Cox proportional hazards model. $\mathrm{P}<0.05$ was considered to indicate a statistically significant difference.

\section{Results}

NUSAPl expression is upregulated in NSCLC tissues. The expression levels of NUSAP1 in NSCLC tissues were investigated using the GENT database. The results demonstrated that NUSAP1 expression was significantly higher in NSCLC tissues compared with that in normal tissues (Fig. 1A). In addition, the mRNA expression levels of NUSAP1 in 35 pairs of human NSCLC and adjacent normal tissues were determined via RT-qPCR. As shown in Fig. 1B, NUSAP1 mRNA expression was significantly higher in NSCLC tissues compared with that in normal tissues. Furthermore, results from the Kaplan-Meier plotter revealed that patients with high NUSAP1 expression exhibited a shorter survival compared with patients with low expression (Fig. 1C). Subsequently, IHC was performed to confirm NUSAP1 protein expression in NSCLC tissues. NUSAP1 expression was scored according to the percentage of positive cells and the staining intensity (Fig. S1). The results revealed that NUSAP1 expression in lung adenocarcinoma and lung squamous cell carcinoma tissues was markedly upregulated compared with that in normal lung tissues (3.37 \pm 2.40 vs. $1.89 \pm 2.00$; $\mathrm{P}=0.001$; Fig. 1D). Moreover, high NUSAP1 expression was significantly associated with large tumor size $(\mathrm{P}=0.005)$, advanced TNM stage $(\mathrm{P}=0.004)$ and lymph node metastasis $(\mathrm{P}=0.026)$, but not with age $(\mathrm{P}=0.454)$, sex $(\mathrm{P}=0.849)$, smoking status $(\mathrm{P}=0.573)$ or histological type $(\mathrm{P}=0.287)$ (Table $\mathrm{I})$. In addition, the results of the Kaplan-Meier survival analysis demonstrated that patients with NSCLC with high NUSAP1 expression had a significantly shorter overall survival than patients with low expression $(\mathrm{P}<0.001$; Fig. 1E). Furthermore, Cox regression analysis revealed that high NUSAP1 expression, tumor size and lymph node metastasis were independent risk factors for poor prognosis in patients with NSCLC (Table III). Next, NUSAP1 protein expression was measured in A549, H1299, HCC827, H358 and BEAS-2B cells. The results demonstrated that the expression levels of NUSAP1 were significantly higher in A549, H1299, HCC827 and H358 cells compared with those in BEAS-2B cells (Fig. 1F).

NUSAPI inhibition suppresses NSCLC cell proliferation, colony formation and invasion. To evaluate the role of NUSAP1 in NSCLC cell progression, H1299 and A549 cells were transfected with NUSAP1 RNAi and a universal NC. As shown in Fig. S2A, H1299 and A549 cells were successfully transfected with NUSAP1 RNAi and a universal NC. Western blotting assays demonstrated that $\mathrm{H} 1299$ and A549 cells transfected with NUSAP1 RNAi exhibited significantly decreased NUSAP1 protein expression compared with cells transfected with the NC (Fig. 2A). The cell function assays revealed that NUSAP1 downregulation significantly suppressed the proliferative (Fig. 2B), colony-forming (Fig. 2C) and invasive (Fig. 2D) abilities of H1299 and A549 cells.

NUSAP1-knockdown inhibits the tumorigenic ability of NSCLC cells. To confirm the effect of NUSAP1 on NSCLC growth in vivo, A549 cells transfected with NUSAP1 RNAi and a universal NC were subcutaneously injected into 5 -week-old nude mice. The results demonstrated that the mean tumor volume in the group injected with NUSAP1-knockdown 
Table III. Cox proportional hazard model analysis for prognostic factors.

\begin{tabular}{|c|c|c|c|c|}
\hline \multirow[b]{2}{*}{ Variables } & \multicolumn{2}{|c|}{ Univariate analysis } & \multicolumn{2}{|c|}{ Multivariate analysis } \\
\hline & $\mathrm{HR}(95 \% \mathrm{CI})$ & P-value & $\mathrm{HR}(95 \% \mathrm{CI})$ & P-value \\
\hline Age ( $\geq 60$ vs. $<60$ years) & $1.153(0.744-1.786)$ & 0.524 & & \\
\hline Sex (Female vs. male) & $0.936(0.597-1.466)$ & 0.771 & & \\
\hline Smoking status (Smoke vs. never smoke) & $1.516(0.980-2.346)$ & 0.062 & & \\
\hline Tumor size ( $\geq 3$ vs. $<3 \mathrm{~cm}$ ) & $1.600(1.031-2.483)$ & $0.036^{\mathrm{a}}$ & $1.680(1.094-2.580)$ & $0.018^{\mathrm{a}}$ \\
\hline $\begin{array}{l}\text { Histological type (Adenocarcinoma vs. } \\
\text { squamous cell carcinoma) }\end{array}$ & $1.121(0.736-1.709)$ & 0.594 & & \\
\hline TNM stage (III+IV vs. I+II) & $2.022(0.919-4.452)$ & 0.080 & & \\
\hline Lymph node metastasis (Yes vs. no) & $2.370(1.075-5.223)$ & $0.032^{\mathrm{a}}$ & $3.870(2.368-6.324)$ & $<0.001^{\mathrm{b}}$ \\
\hline NUSAP1 (High vs. now) & $1.824(1.156-2.877)$ & $0.010^{\mathrm{a}}$ & $1.868(1.186-2.940)$ & $0.007^{\mathrm{b}}$ \\
\hline
\end{tabular}

${ }^{\mathrm{a}} \mathrm{P}<0.05 ;{ }^{\mathrm{b}} \mathrm{P}<0.01$. HR, hazard ratio; NUSAP1, nucleolar and spindle-associated protein 1.
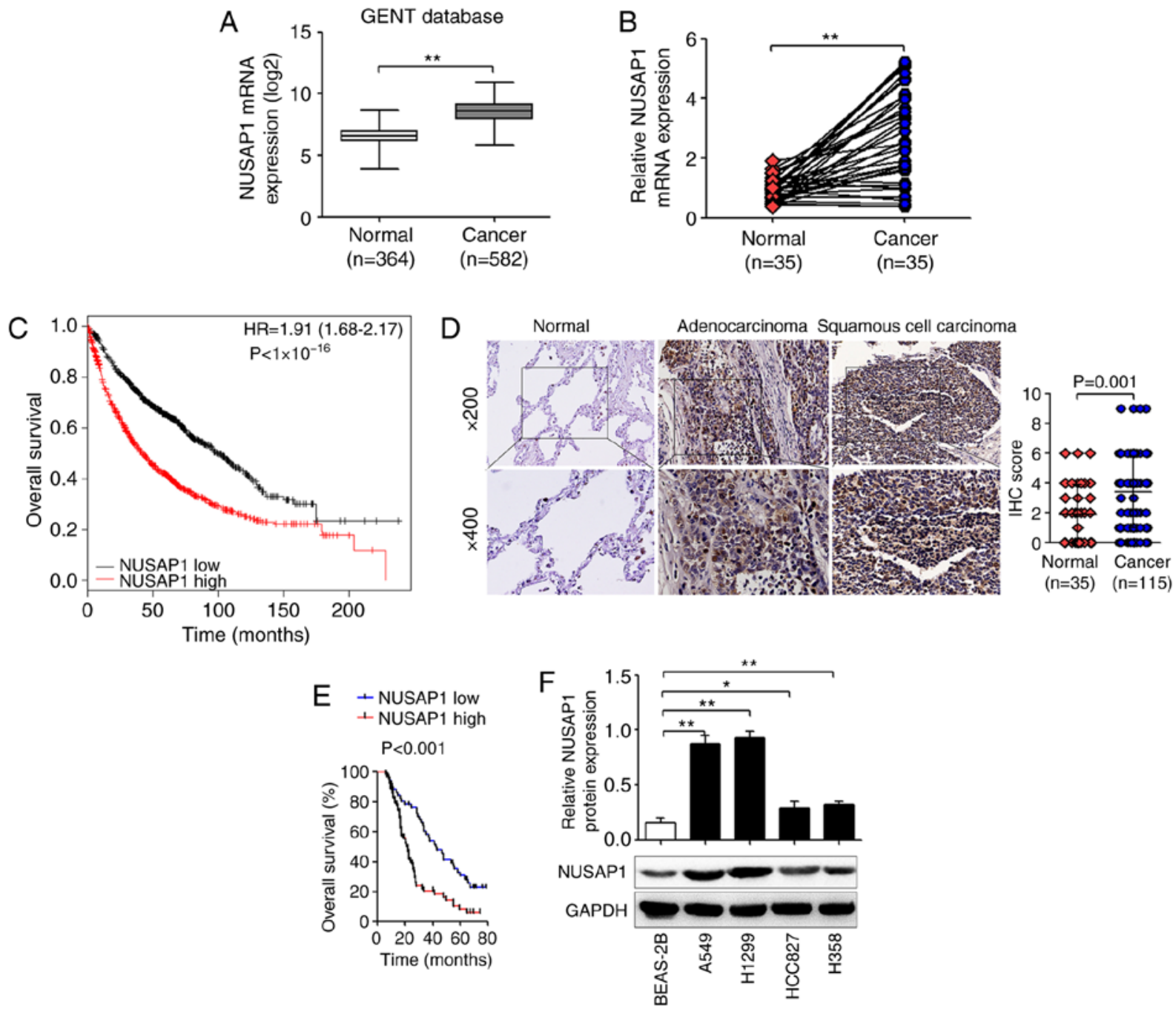

Figure 1. NUSAP1 expression is upregulated in NSCLC tissues and cell lines, and is associated with a poor prognosis in patients with NSCLC. (A) NUSAP1 mRNA was highly expressed in 582 NSCLC samples compared with in 364 normal tissues based on the GENT database. (B) Reverse transcription-quantitative PCR analysis of NUSAP1 mRNA expression in NSCLC tissues and matched adjacent normal lung tissues. (C) Patients with high NUSAP1 expression exhibited shorter survival using the Kaplan-Meier plotter. (D) Representative images of immunohistochemistry analysis of NUSAP1 protein expression in NSCLC and normal adjacent tissues (magnification, x200 and x400) are shown in the left panels. The right panel shows that NUSAP1 protein levels were significantly upregulated in 115 NSCLC samples compared with in 35 adjacent normal tissues. (E) Kaplan-Meier analysis of overall survival stratified by low NUSAP1 expression $(n=51)$ and high NUSAP1 expression $(n=64)$ is shown. $(F)$ Western blotting was used to examine NUSAP1 expression in four NSCLC cell lines (A549, H1299, HCC827 and H358) and one normal human lung epithelial cell line (BEAS-2B). ${ }^{*}<<0.05$; ${ }^{* *} \mathrm{P}<0.01$. NSCLC, non-small cell lung cancer; NUSAP1, nucleolar and spindle-associated protein 1; GENT, Gene Expression of Normal and Tumor tissues. 

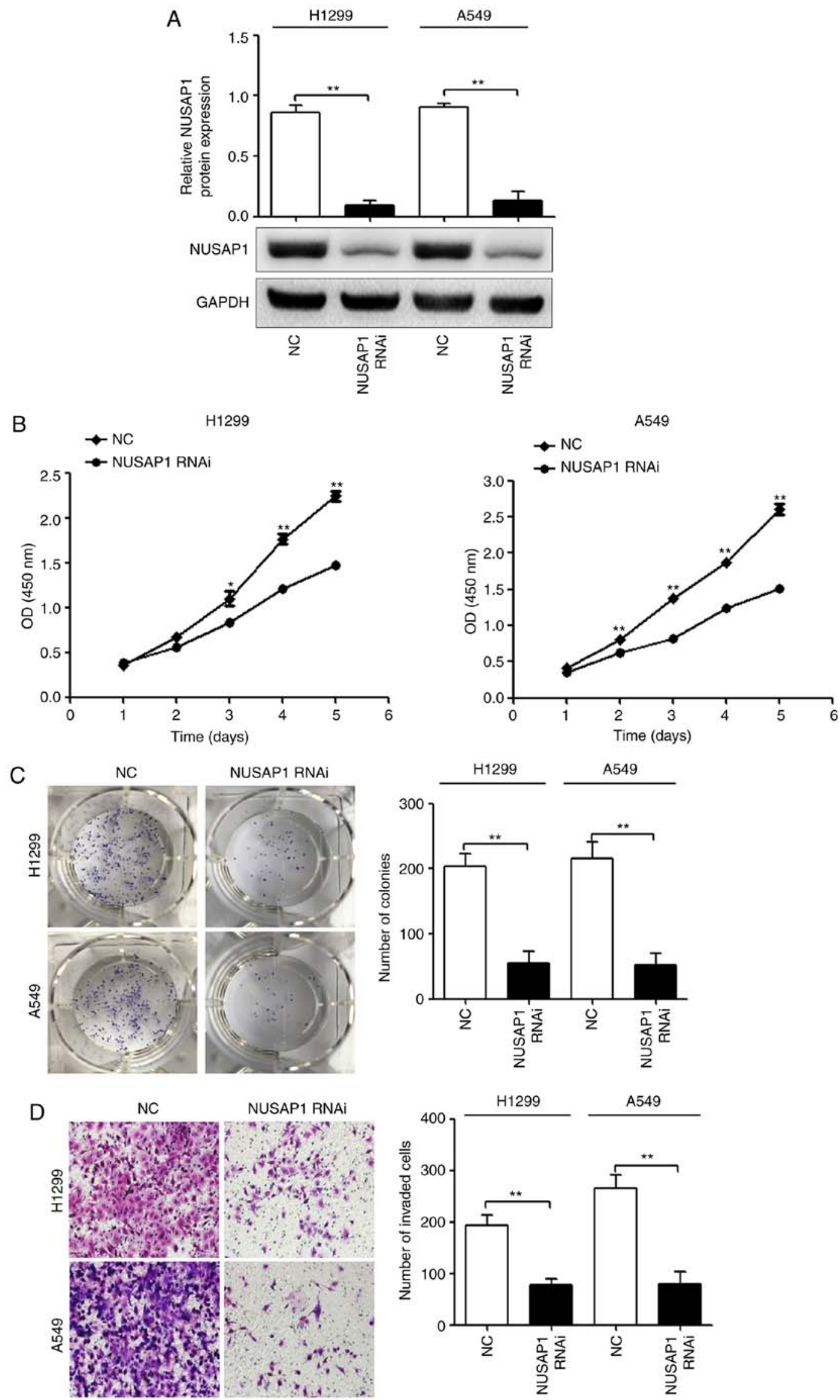

Figure 2. NUSAP1 acts as an oncogene in NSCLC cells. H1299 and A549 cells were transfected with a NUSAP1 shRNA plasmid (NUSAP1 RNAi) or a universal NC plasmid. (A) NUSAP1 protein expression was determined by western blotting. Proliferation, colony formation and invasion of H1299 and A549 cells transfected with NUSAP1 RNAi or a universal NC were determined by (B) Cell Counting Kit-8, (C) colony formation and (D) Transwell assays, respectively (magnification, $\mathrm{x} 200$ ). ${ }^{*} \mathrm{P}<0.05 ;{ }^{* * *} \mathrm{P}<0.01$ vs. NUSAP1 RNAi. NC, negative control; NSCLC, non-small cell lung cancer; NUSAP1, nucleolar and spindle-associated protein 1; shRNA, short hairpin RNA; RNAi, RNA interference; OD, optical density. 

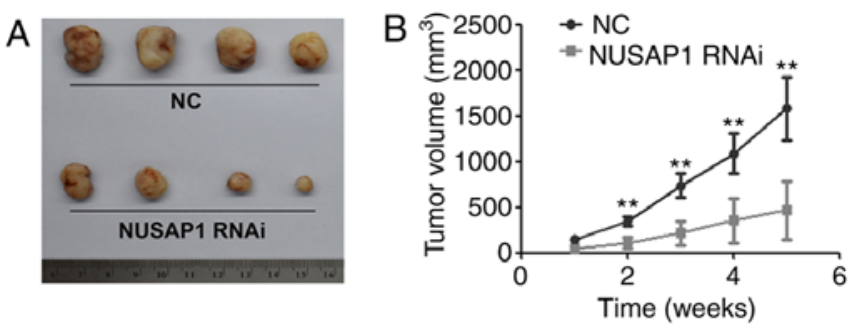

Figure 3. NUSAP1-knockdown in A549 cells represses xenograft tumor growth in vivo. A549 cells stably transfected with the NUSAP1 shRNA vector (NUSAP1 RNAi) and a universal NC were subcutaneously injected into nude mice at a concentration of $1 \times 10^{7}$ cells in $100 \mu 1$ PBS. Tumor volumes were measured weekly. The mice were sacrificed on the fifth week. (A) Representative images of the effect of NUSAP1-knockdown on tumors. (B) Tumor volumes were measured at the indicated time points in all mice. ${ }^{* *} \mathrm{P}<0.01$ vs. NUSAP1 RNAi. NC, negative control; NUSAP1, nucleolar and spindle-associated protein 1; shRNA, short hairpin RNA; RNAi, RNA interference.

cells was significantly smaller compared with that in the NC group (Fig. 3).

MEF2D transcriptionally regulates NUSAP1 expression. To investigate the molecular mechanisms that control NUSAP1 expression in NSCLC, the promoter region of NUSAP1 was scanned for known transcription factors using the JASPAR database and GeneCard. Several putative transcription factors, including MEF2D, ZEB1 and E2F1, were selected. To determine whether MEF2D, ZEB1 and E2F1 affected NUSAP1 expression, A549 cells were transfected with shRNA plasmids against MEF2D (MEF2D RNAi), ZEB1 (ZEB1 RNAi) or E2F1 (E2F1 RNAi), or a universal NC plasmid. The protein expression levels of MEF2D, ZEB1 and E2F1 were determined by western blotting. The present results revealed that the protein expression levels of MEF2D, ZEB1 and E2F1 were significantly inhibited by MEF2D RNAi, ZEB1 RNAi and E2F1 RNAi, respectively (Fig. S3A). As shown in Fig. S3B, MEF2D-knockdown significantly inhibited the mRNA expression levels of NUSAP1; however, neither ZEB1-nor E2F1-knockdown repressed the mRNA expression levels of NUSAP1. In addition, the results revealed that the promoter region (from 1,519 to $1,508 \mathrm{bp}$ ) of NUSAP1 had a putative MEF2D-binding site (Fig. 4A). Therefore, it was hypothesized that MEF2D, as an important transcription factor, may transcriptionally regulate NUSAP1 expression, which may be one of the key regulatory mechanisms underlying the overexpression of NUSAP1 in NSCLC. To determine whether NUSAP1 was a direct target of MEF2D, MEF2D-knockdown and overexpressing cell lines were constructed using H1299, A549 and HCC827 cells. As shown in Fig. S2A and B, H1299 and A549 cells were successfully transfected with a cell transfection efficiency $>95 \%$. Western blot assays demonstrated that H1299 and A549 cells transfected with MEF2D RNAi exhibited significantly decreased MEF2D protein expression compared with cells transfected with the NC, while HCC827 cells transfected with MEF2D overexpression vectors exhibited significantly increased MEF2D protein expression compared with control cells (Fig. 4B). In addition, RT-qPCR and western blot analyses revealed that MEF2D-knockdown significantly inhibited NUSAP1 mRNA and protein expression in H1299 and A549 cells (Fig. 4C and D). On the other hand, MEF2D overexpression in HCC827 cells significantly increased NUSAP1 mRNA and protein expression (Fig. 4C and D). Subsequently, to determine whether NUSAP1 is a direct target of MEF2D, wild-type and mutant NUSAP1 promoter luciferase reporter vectors were constructed. As shown in Fig. 4E, MEF2D downregulation significantly decreased the promoter activity of NUSAP1 in H1299 and A549 cells. In addition, MEF2D upregulation induced the promoter activity of NUSAP1 in HCC827 cells, while the mutant NUSAP1 promoter abolished the promotional effect of MEF2D upregulation on luciferase activity (Fig. 4F). These results supported the hypothesis that MEF2D regulated NUSAP1 transcription by binding to the NUSAP1 promoter. Additionally, the GENT database revealed that MEF2D mRNA expression was significantly upregulated in NSCLC tissues compared with in normal tissues and was positively correlated with NUSAP1 expression (Fig. 4G). In the present study, MEF2D mRNA expression in the 35 pairs of human NSCLC and adjacent normal tissues was determined via RT-qPCR. As shown in Fig. 4H, MEF2D mRNA expression was significantly higher in NSCLC tissues compared with that in normal tissues $(\mathrm{P}<0.001)$. In addition, MEF2D mRNA expression was positively correlated with NUSAP1 mRNA expression (Fig. 4H).

NUSAP1 restoration reverses the effects of $M E F 2 D-k n o c k d o w n$ on NSCLC cells. To confirm that MEF2D exerts its effects on NSCLC cells via NUSAP1, NUSAP1 overexpression plasmids were constructed and transfected into H12299 and A549 cells. As shown in Fig. 5A, NUSAP1 protein expression was significantly increased in H12299 and A549 cells. Subsequently, MEF2D RNAi together with NUSAP1 overexpression plasmids were transfected into H12299 and A549 cells. As confirmed via western blotting, NUSAP1 expression was restored in MEF2D RNAi-transfected NSCLC cells using the NUSAP1 expression plasmid (Fig. 5B). In addition, it was observed that the restoration of NUSAP1 expression rescued the proliferation, colony formation and invasion of NSCLC cells suppressed by MEF2D-knockdown (Fig. 5C-E).

Both MEF2D and NUSAP1 promote the activation of the Wnt/ $\beta$-catenin signaling pathway. In NSCLC, Wnt/ $\beta$-catenin signaling is involved in promoting tumor aggressiveness and resistance to chemotherapy and radiation (25). In addition, NUSAP1 induces cervical cancer cell metastasis by activating Wnt/ $\beta$-catenin signaling (13). In gastric cancer, MEF2D contributes to cancer cell proliferation by regulating the activation of the $\mathrm{Wnt} / \beta$-catenin signaling pathway (26). Thus, Wnt/ $\beta$-catenin signaling may contribute to MEF2D/NUSAP1-regulated NSCLC progression. The results of the present study revealed that either MEF2D- or NUSAP1-knockdown repressed the accumulation and nuclear translocation of $\beta$-catenin and the translation of Wnt targets, including cyclin D1, c-Myc and MMP7 (Fig. 6A and B).

MEF $2 D$ promotes the activation of the Wnt/ $\beta$-catenin signaling pathway via NUSAP1. To further determine the role of NUSAP1 in the effects of MEF2D on the activation of the Wnt/ $\beta$-catenin signaling pathway, NUSAP1 expression was rescued using NUSAP1 overexpression plasmid vectors in cells transfected with MEF2D RNAi. As shown in 

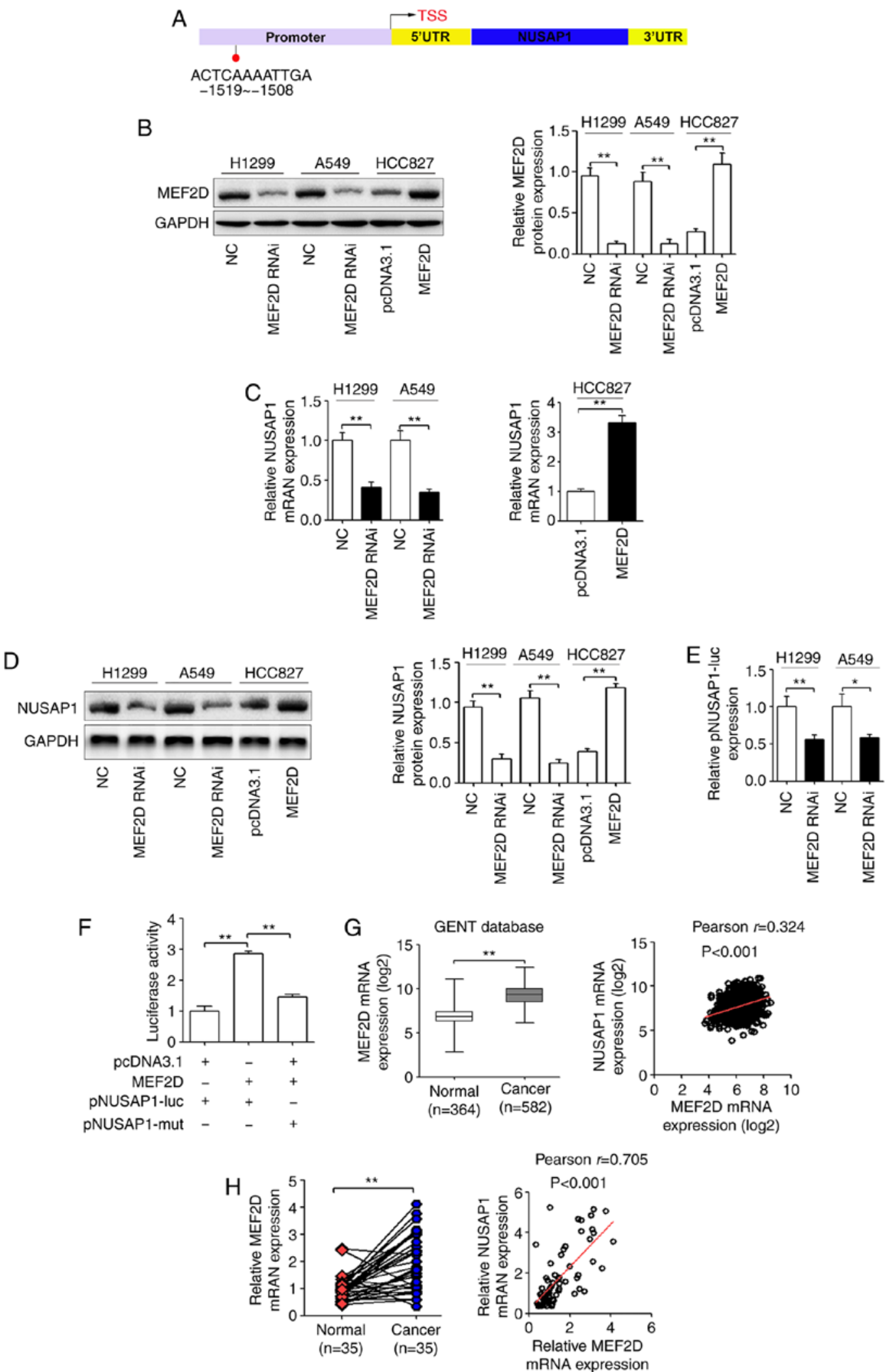

Figure 4. NUSAP1 serves as the effector of MEF2D in NSCLC cells. (A) Prediction of the putative MEF2D-binding site in the promoter of NUSAP1 based on the JASPAR database. H1299 and A549 cells were transfected with a MEF2D shRNA plasmid (MEF2D RNAi) or a universal NC, and HCC827 cells were transfected with a MEF2D overexpression plasmid or a pcDNA3.1 control plasmid. (B) Protein expression levels of MEF2D. (C) mRNA and (D) protein expression levels of NUSAP1 determined via RT-qPCR and western blotting, respectively. (E) Luciferase reporter assay demonstrated that MEF2D-knockdown significantly inhibited the luciferase activity of the wild-type NUSAP1 promoter reporter gene (pNUSAP1-luc). (F) MEF2D overexpression induced the promoter activity of NUSAP1 in HCC827 cells, while the mutated NUSAP1 promoter reversed the effect of MEF2D overexpression. (G) MEF2D expression was upregulated in lung cancer tissues compared with in normal lung tissues from the GENT database and was positively correlated with NUSAP1 expression in lung cancer according to this database. (H) RT-qPCR analysis of MEF2D mRNA expression in NSCLC and matched adjacent normal lung tissues. Pearson's correlation analysis was used to explore the association between MEF2D and NUSAP1 expression. ${ }^{*} \mathrm{P}<0.05 ;{ }^{* *} \mathrm{P}<0.01$. MEF2D, myocyte enhancer factor $2 \mathrm{D}$; NC, negative control; NSCLC, non-small cell lung cancer; NUSAP1, nucleolar and spindle-associated protein 1; RT-qPCR, reverse transcription-quantitative PCR; shRNA, short hairpin RNA; RNAi, RNA interference; UTR, untranslated region; mut, mutated; GENT, Gene Expression of Normal and Tumor tissues. 
A

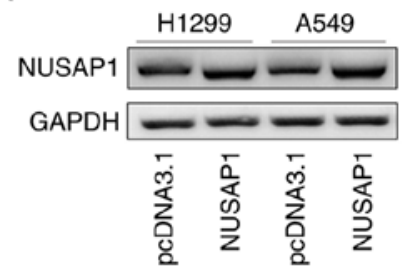

B

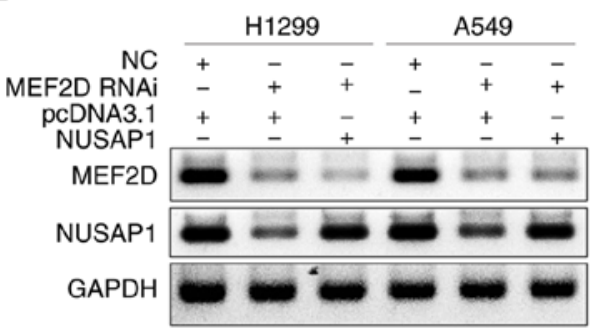

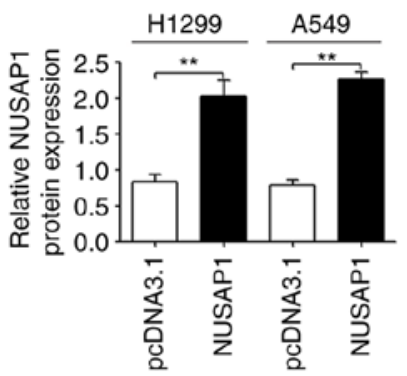

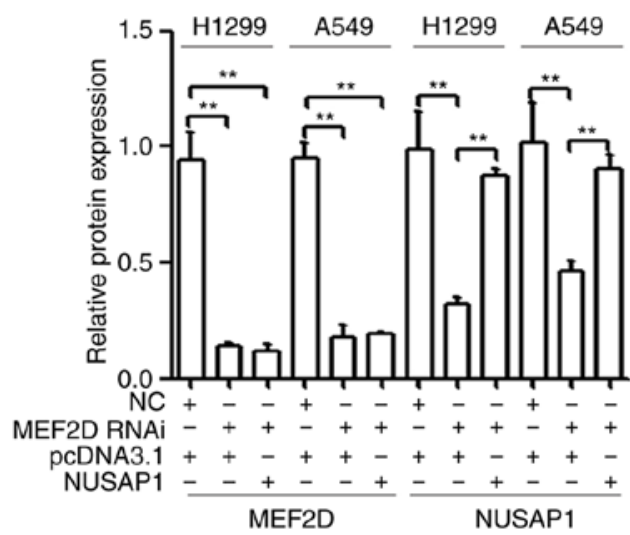

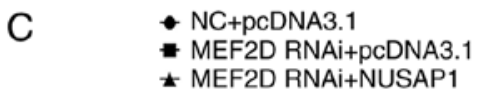
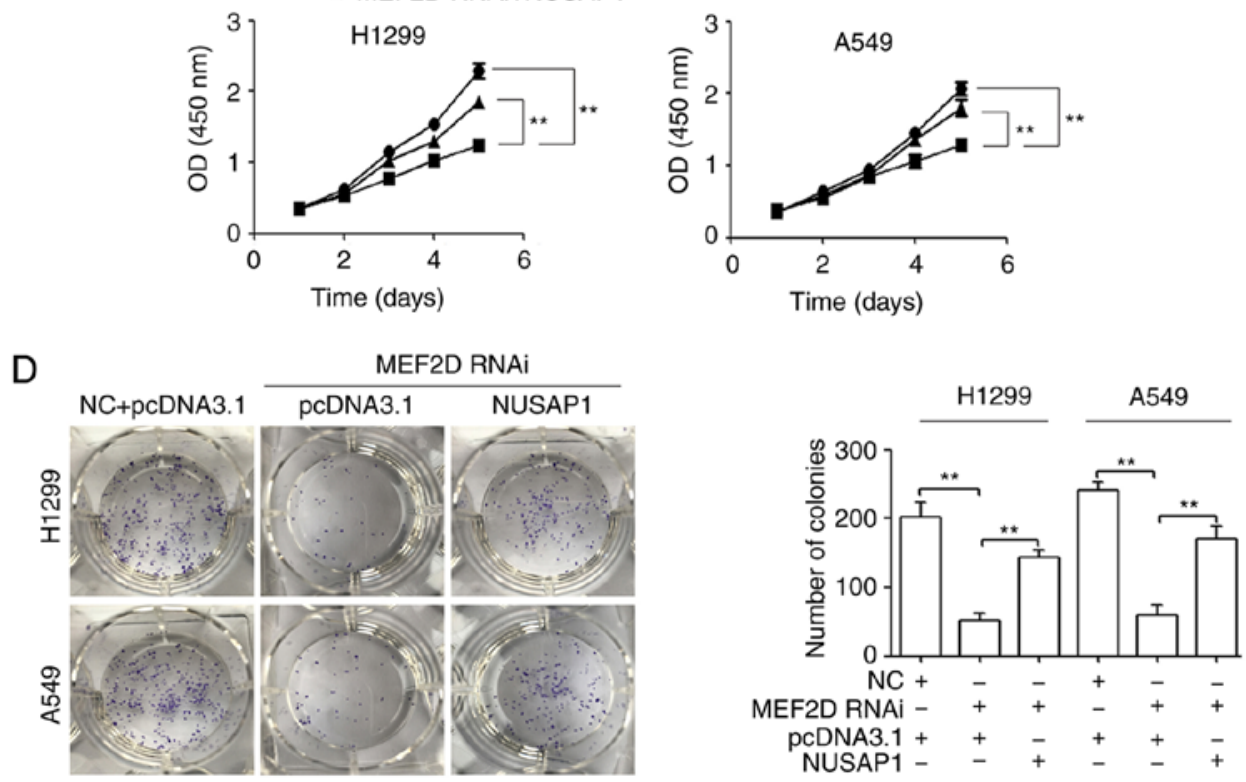

$\mathrm{E}$

MEF2D RNAi
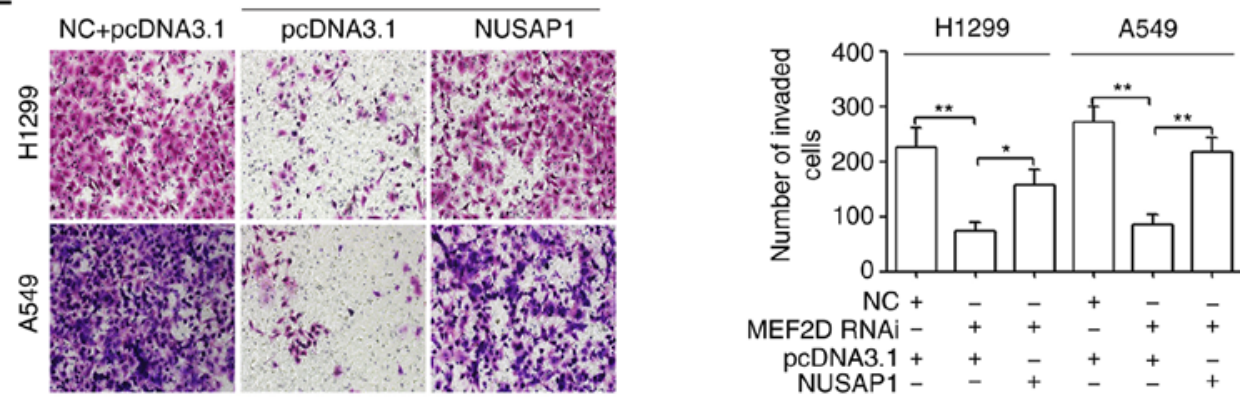

Figure 5. Restoration of NUSAP1 expression partially reverses the effect of MEF2D on NSCLC cells. (A) H1299 and A549 cells were transfected with a NUSAP1 overexpression plasmid or a pcDNA3.1 control expression plasmid, and NUSAP1 protein expression was analyzed by western blotting. A549 and H1299 cells were co-transfected with NC or MEF2D RNAi and pcDNA3.1 or NUSAP1 overexpression plasmid. (B) Western blotting was used to determine MEF2D and NUSAP1 protein expression. The restoration of NUSAP1 protein expression rescued the inhibition of the (C) proliferation, (D) colony formation and (E) invasion of NSCLC cells caused by MEF2D-knockdown (magnification, $\mathrm{x} 200$ ). ${ }^{*} \mathrm{P}<0.05$; ${ }^{* *} \mathrm{P}<0.01$. MEF2D, myocyte enhancer factor $2 \mathrm{D}$; NC, negative control; NSCLC, non-small cell lung cancer; NUSAP1, nucleolar and spindle-associated protein 1; RNA, RNA interference; OD, optical density. 
A
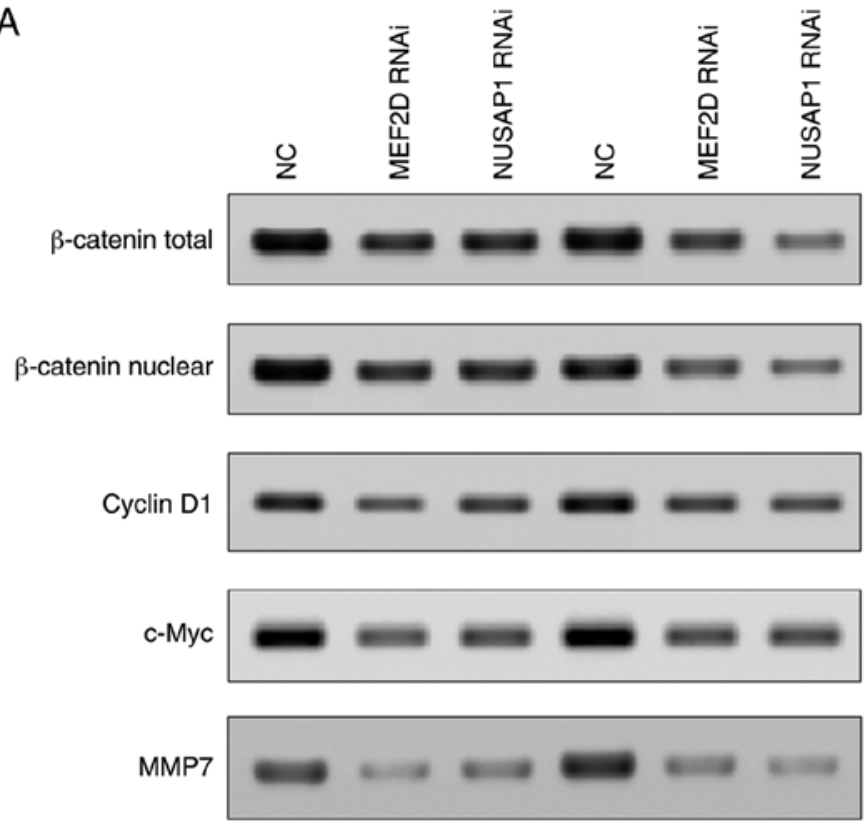

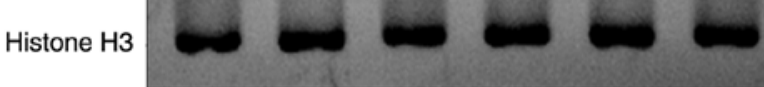

GAPDH
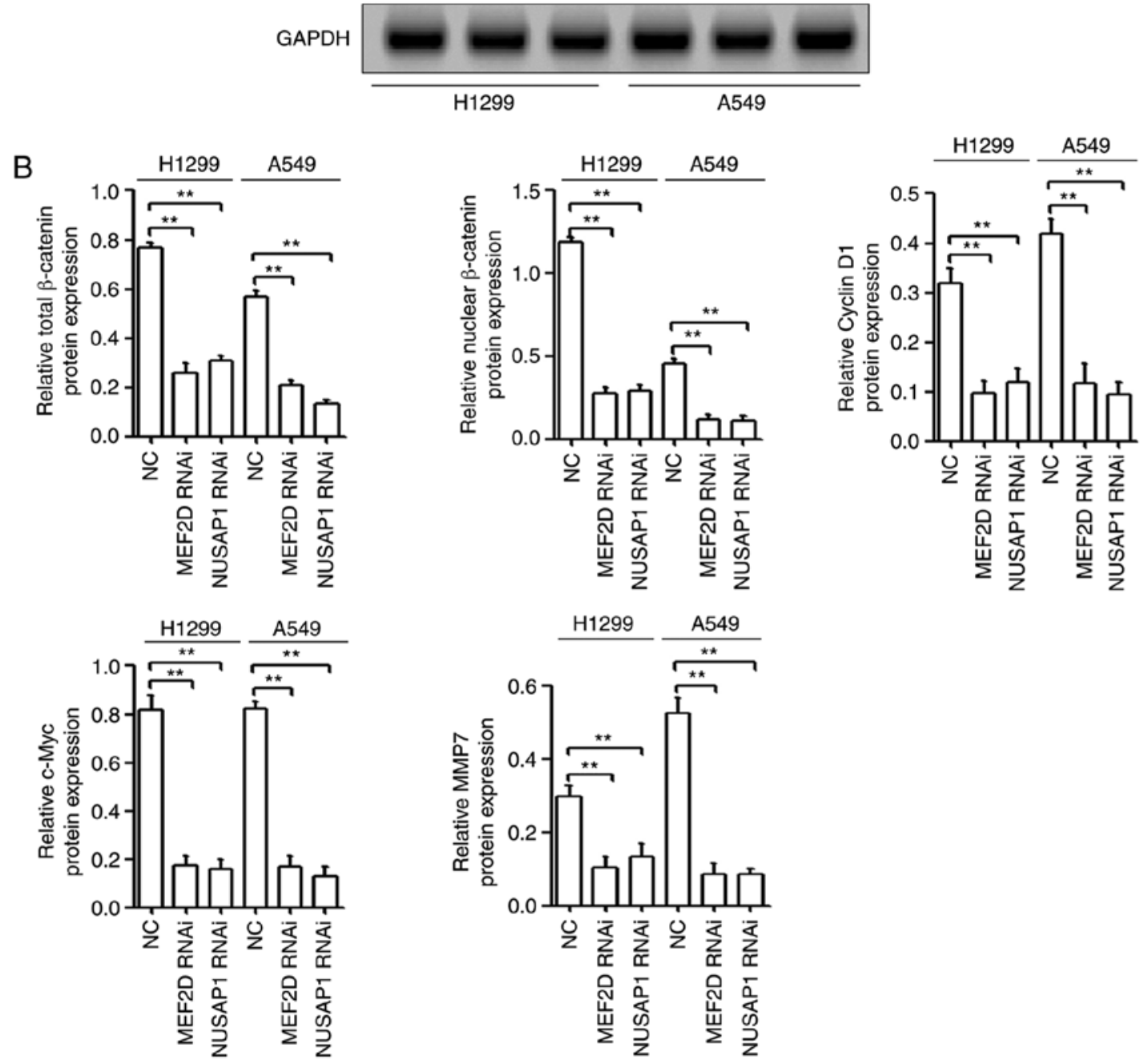

Figure 6. Both MEF2D and NUSAP1 activate the Wnt/B-catenin signaling pathway in NSCLC. (A) H1299 and A549 cells were transfected with a NUSAP1 shRNA plasmid (NUSAP1 RNAi), a MEF2D shRNA plasmid (MEF2D RNAi) or a universal NC plasmid. The accumulation and nuclear translocation of $\beta$-catenin and the translation of Wnt targets, including cyclin D1, c-Myc and MMP7, were determined by western blotting. (B) Quantification of western blotting results from triplicates. ${ }^{* *} \mathrm{P}<0.01$. MEF2D, myocyte enhancer factor 2D; NC, negative control; NSCLC, non-small cell lung cancer; NUSAP1, nucleolar and spindle-associated protein 1; shRNA, short hairpin RNA; RNAi, RNA interference; MMP, matrix metallopeptidase. 

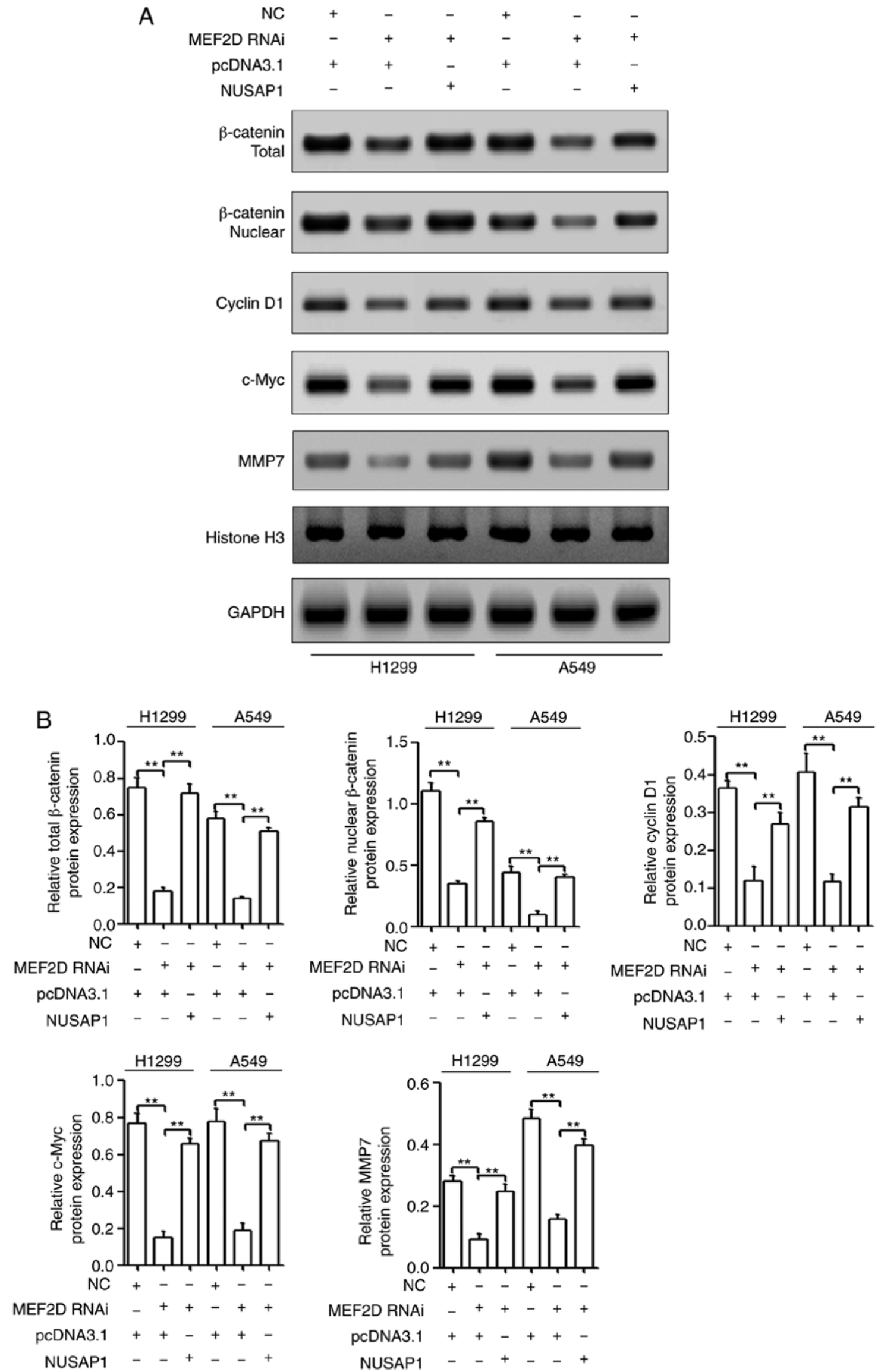

Figure 7. MEF2D activates the Wnt/B-catenin signaling pathway via NUSAP1 in NSCLC. (A) A549 and H1299 cells were co-transfected with NC or MEF2D RNAi and pcDNA3.1 or NUSAP1 overexpression plasmid. Western blotting was used to determine the accumulation and nuclear translocation of $\beta$-catenin and the translation of Wnt targets, including cyclin D1, c-Myc and MMP7. (B) Quantification of western blotting results from triplicates. ${ }^{* *} \mathrm{P}<0.01$. MEF2D, myocyte enhancer factor 2D; NC, negative control; NSCLC, non-small cell lung cancer; NUSAP1, nucleolar and spindle-associated protein 1; shRNA, short hairpin RNA; RNAi, RNA interference; MMP, matrix metallopeptidase. 
Fig. 7A and B, NUSAP1 overexpression reversed the suppressive effects of MEF2D downregulation on the activation of the Wnt/ $\beta$-catenin signaling pathway. Overall, the present findings indicated that MEF2D may promote NSCLC progression via the NUSAP1/Wnt/ $/$-catenin signaling axis.

\section{Discussion}

NSCLC remains one of the most lethal types of cancer worldwide, largely due to the majority of patients being diagnosed at the locally advanced or metastatic stage (27). Thus, exploring new biomarkers and elucidating the underlying mechanisms of NSCLC progression are fundamental for the development of novel therapeutic approaches for NSCLC. As reported by Li et al (13), NUSAP1 is upregulated in cervical cancer tissues and cell lines, and is associated with metastasis and poor clinical outcomes of patients. Additionally, a previous study revealed that NUSAP1 is upregulated in lung cancer (15). Thus, NUSAP1 may be a novel prognostic marker of NSCLC. In the present study, the results from the GENT database, RT-qPCR analysis and IHC staining demonstrated that the mRNA and protein expression levels of NUSAP1 were significantly upregulated in NSCLC tissues compared with those in normal tissues. High NUSAP1 expression was significantly associated with large tumor size, advanced TNM stage and lymph node metastasis. Furthermore, multivariate Cox regression analysis revealed that NUSAP1 expression was an independent risk factor for shorter overall survival. The present results indicated the prognostic significance of NUSAP1 in NSCLC.

Recently, accumulating evidence has indicated that NUSAP1 acts as an oncogene in different types of malignant tumor $(9,13,14,28,29)$. For example, NUSAP1 inhibition in HCC Huh7 cells repressed their proliferation, survival, migration and growth as xenograft tumors in nude mice (14). Overexpression of NUSAP1 can modulate the expression levels of family with sequence similarity 101 , member B, thereby enhancing the invasion and migration of prostate cancer cells (9). Furthermore, NUSAP1-knockdown represses cell proliferation, migration and invasion in human colorectal cancer (28). In addition, NUSAP1 enhances the invasive ability of astrocytoma cells by activating the Hedgehog signaling pathway (29). $\mathrm{Xu}$ et al (16) demonstrated that NUSAP1-knockdown inhibits NSCLC cell proliferation, migration and invasion by regulating BTG2/PI3K/Akt signaling. The results of the present study revealed that NUSAP1 downregulation suppressed NSCLC cell proliferation, colony formation and invasion. Moreover, NUSAP1 downregulation in NSCLC cells markedly decreased their tumorigenicity in nude mice. Thus, NUSAP1 functioned as an oncogene in NSCLC cells. However, the mechanism underlying the role of NUSAP1 in the regulation of NSCLC progression remains unknown. Therefore, further studies are required to explore the potential mechanism of action of NUSAP1 in NSCLC progression.

Several studies have reported that transcription factors, such as E2F1 and lin-9 DREAM MuvB core complex component can transcriptionally regulate NUSAP1 by binding to the NUSAP1 promoter region $(30,31)$. Thus, regulation by transcription factors may be a key mechanism underlying the high expression levels of NUSAP1 in NSCLC. To further explore the mechanism of action of NUSAP1 in
NSCLC, known transcription factors were searched using the JASPAR database and GeneCard. Several putative transcription factors, including MEF2D, ZEB1 and E2F1, were selected. It was previously reported that MEF2D directly binds to the region upstream from the transcription sites of reprimo TP53-dependent G2 arrest mediator homolog, cyclin-dependent kinase inhibitor $1 \mathrm{~A}$ and growth arrest and DNA damage inducible $\alpha / \beta(G A D D 45 \mathrm{~A} / \mathrm{B})$, and regulates the activity of these promoters in HCC (32). Additionally, MEF2D is involved in the regulation of tumor cell proliferation, invasion and migration in NSCLC $(33,34)$. ZEB1 expression is associated with tumor grade and metastasis in lung cancer, and has been reported to induce invasion and metastases in NSCLC (35). E2F1 expression is significantly increased in lung cancer and is required for tumor growth (36). In the present study, MEF2D-knockdown significantly inhibited the mRNA expression levels of NUSAP1; however, neither ZEB1-nor E2F1-knockdown repressed the mRNA expression levels of NUSAP1. In addition, MEF2D-knockdown inhibited NUSAP1 expression at both the mRNA and protein level, while MEF2D overexpression increased the mRNA and protein expression levels of NUSAP1. Further investigation indicated that NUSAP1 was a direct target of MEF2D in NSCLC. First, the luciferase assay revealed that MEF2D inhibition significantly decreased the promoter activity of NUSAP1. Second, MEF2D overexpression induced the promoter activity of NUSAP1 in HCC 827 cells, while the mutant NUSAP1 promoter abolished the promotional effect of MEF2D overexpression on luciferase activity. Third, MEF2D expression was significantly upregulated in NSCLC and was positively correlated with NUSAP1 expression. Fourth, MEF2D-knockdown exerted an effect similar to that of NUSAP1 depletion, including inhibition of NSCLC cell proliferation, colony formation and invasion. Furthermore, NUSAP1 restoration reversed the inhibition of proliferation, colony formation and invasion of NSCLC cells caused by MEF2D-knockdown. The current results indicated that MEF2D regulated the proliferation, colony formation and invasion of NSCLC cells via NUSAP1.

It is well known that the Wnt/ $\beta$-catenin signaling pathway serves a pivotal role in regulating NSCLC cell proliferation, motility and invasion (25). Additionally, NUSAP1 upregulation promotes cervical cancer cell metastasis by activating Wnt/ $\beta$-catenin signaling (13). In vascular smooth muscle cells, MEF2D induces cell proliferation via regulating the Wnt/ $\beta$-catenin signaling pathway (37). In gastric cancer, MEF2D-knockdown inhibits cell proliferation by regulating the activation of $\mathrm{Wnt} / \beta$-catenin signaling (26). Consistently with the aforementioned studies, the present study revealed that either MEF2D- or NUSAP1-knockdown repressed the accumulation and nuclear translocation of $\beta$-catenin and the translation of Wnt targets, including cyclin D1 and c-Myc, which are associated with cell proliferation $(38,39)$, and MMP7, which is associated with cell mobility (40). Hence, it was inferred that MEF2D may activate the $\mathrm{Wnt} / \beta$-catenin signaling pathway by regulating NUSAP1 expression in NSCLC cells. The current results demonstrated that NUSAP1 overexpression reversed the effect of MEF2D-knockdown on the accumulation and nuclear translocation of $\beta$-catenin and cyclin D1, c-Myc and MMP7 protein expression. Overall, the present findings suggested that the regulation of NUSAP1 by 
MEF2D may contribute to the activation of the $\mathrm{Wnt} / \beta$-catenin signaling pathway.

p53, a tumor suppressor, serves an important role in repressing malignant progression and is mutated in $>50 \%$ of human primary tumors (41). In addition, mutant p53 occurs in $\sim 50 \%$ of NSCLC cases and promotes NSCLC cell proliferation, invasion and EMT $(42,43)$. Notably, mutant p53 (R175H) regulates the transcriptional expression of MEF2D in SKOV3 cells (44). In the present study, NUSAP1 was involved in the regulation of proliferation and invasion. This property may be shared by mutant $\mathrm{p} 53$. Thus, the association between mutant p53 and the MEF2D/NUSAP1 pathway requires further exploration. However, there are some limitations in the present study. For example, the association between mutant p53 and MEF2D expression was not investigated in NSCLC tissues. In addition, whether mutant p53 may drive NSCLC progression by directly regulating MEF2D requires further confirmation.

In conclusion, NUSAP1 expression was upregulated in NSCLC tissues. Additionally, either NUSAP1 or MEF2D depletion inhibited the proliferation, colony formation and invasion of NSCLC cells. Mechanistically, MEF2D directly regulated the transcriptional expression of NUSAP1 by binding to its promoter in NSCLC cells. In addition, MEF2D may regulate NSCLC progression via modulating the NUSAP1/Wnt/ $\beta$-catenin signaling axis, which may indicate new targets for NSCLC therapy in the future.

\section{Acknowledgements}

Not applicable.

\section{Funding}

The present study was supported by the Science and Technology Project of Yuzhong, Chongqing (grant no. 20150128), the Natural Science Foundation of Guangxi (grant no. 2019GXNSFAA245066) and the Education Department Science Foundation of Guangxi Zhuang Autonomous Region (grant no. 2017KY0511).

\section{Availability of data and materials}

The datasets used and/or analyzed during the current study are available from the corresponding author on reasonable request.

\section{Authors' contributions}

BL, WH and SH designed the study. BL, PW, JX, XF, GY and SL performed the experiments. BL, BC, ZZ, WL and $\mathrm{HW}$ analyzed and interpreted the data. BL and $\mathrm{WH}$ wrote the manuscript. SH supervised the study. All authors have read and approved the final version of the manuscript and agree to be accountable for all aspects of the research in ensuring that the accuracy and integrity of any part of the work are appropriately investigated and resolved.

\section{Ethics approval and consent to participate}

The protocol of the present study was approved by the Ethics Committee of Chongqing General Hospital (Chongqing,
China). All patients provided written informed consent. All animal studies were approved by the Animal Care Committee of Youjiang Medical University for Nationalities (Guangxi, China) and complied with the recommendations of the Chinese Guidelines for the Care and Use of Laboratory Animals.

\section{Patient consent for publication}

Not applicable.

\section{Competing interests}

The authors declare that they have no competing interests.

\section{References}

1. Siegel RL, Miller KD and Jemal A: Cancer statistics, 2018. CA Cancer J Clin 67: 7-30, 2018.

2. Domvri K, Zarogoulidis P, Darwiche K, Browning RF, Li Q, Turner JF, Kioumis I, Spyratos D, Porpodis K, Papaiwannou A, et al: Molecular targeted drugs and biomarkers in NSCLC, the evolving role of individualized therapy. J Cancer 4: 736-754, 2013.

3. Kim KW, Myers CJ, Jung DK and Lu B: NVP-BEZ-235 enhances radiosensitization via blockade of the PI3K/mTOR pathway in cisplatin-resistant non-small cell lung carcinoma. Genes Cancer 5: 293-302, 2014.

4. Hussain S, Benavente SB, Nascimento E, Dragoni I, Kurowski A, Gillich A, Humphreys P and Frye M: The nucleolar RNA methyltransferase Misu (NSun2) is required for mitotic spindle stability. J Cell Biol 186: 27-40, 2009.

5. Li C, Zhang Y, Yang Q, Ye F, Sun SY, Chen ES and Liou YC: NuSAP modulates the dynamics of kinetochore microtubules by attenuating MCAK depolymerisation activity. Sci Rep 6: 18773, 2016.

6. Ribbeck K, Groen AC, Santarella R, Bohnsack MT, Raemaekers T, Köcher T, Gentzel M, Görlich D, Wilm M, Carmeliet G, et al: NuSAP, a mitotic RanGTP target that stabilizes and cross-links microtubules. Mol Biol Cell 17: 2646-2660, 2006.

7. Kokkinakis DM, Liu X and Neuner RD: Modulation of cell cycle and gene expression in pancreatic tumor cell lines by methionine deprivation (methionine stress): Implications to the therapy of pancreatic adenocarcinoma. Mol Cancer Ther 4: 1338-1348, 2005.

8. Ryu B, Kim DS, DeLuca AM and Alani RM: Comprehensive expression profiling of tumor cell lines identifies molecular signatures of melanoma progression. PLoS One 2: e594, 2007.

9. Gordon CA, Gong X, Ganesh D and Brooks JD: NUSAP1 promotes invasion and metastasis of prostate cancer. Oncotarget 8: 29935-29950, 2017.

10. Chen DT, Nasir A, Culhane A, Venkataramu C, Fulp W, Rubio R, Wang T, Agrawal D, McCarthy SM, Gruidl M, et al: Proliferative genes dominate malignancy-risk gene signature in histologically-normal breast tissue. Breast Cancer Res Treat 119: 335-346, 2010.

11. Liu R, Guo CX and Zhou HH: Network-based approach to identify prognostic biomarkers for estrogen receptor-positive breast cancer treatment with tamoxifen. Cancer Biol Ther 16: 317-324, 2015.

12. Cuzick J, Swanson GP, Fisher G, Brothman AR, Berney DM, Reid JE, Mesher D, Speights VO, Stankiewicz E, Foster CS, et al: Prognostic value of an RNA expression signature derived from cell cycle proliferation genes in patients with prostate cancer: A retrospective study. Lancet Oncol 12: 245-255, 2011.

13. Li H, Zhang W, Yan M, Qiu J, Chen J, Sun X, Chen X, Song L and Zhang Y: Nucleolar and spindle associated protein 1 promotes metastasis of cervical carcinoma cells by activating Wnt/ $\beta$-catenin signaling. J Exp Clin Cancer Res 38: 33, 2019.

14. Roy S, Hooiveld GJ, Seehawer M, Caruso S, Heinzmann F, Schneider AT, Frank AK, Cardenas DV, Sonntag R, Luedde M, et al: microRNA $193 \mathrm{a}-5 \mathrm{p}$ regulates levels of Nucleolar- and spindle-associated Protein 1 to suppress hepatocarcinogenesis. Gastroenterology 155: 1951-1966, 2018. 
15. Bidkhori G, Narimani Z, Hosseini Ashtiani S, Moeini A, Nowzari-Dalini A and Masoudi-Nejad A: Reconstruction of an integrated genome-scale co-expression network reveals key modules involved in lung adenocarcinoma. PLoS One 8: e67552, 2013.

16. Xu Z, Wang Y, Xiong J, Cui F, Wang L and Peng H: NUSAP1 knockdown inhibits cell growth and metastasis of non-small-cell lung cancer through regulating BTG2/PI3K/Akt signaling. J Cell Physiol 235: 3886-3893, 2020.

17. Kay FU, Kandathil A, Batra K, Saboo SS, Abbara S and Rajiah P: Revisions to the tumor, node, metastasis staging of lung cancer (8th edition): Rationale, radiologic findings and clinical implications. World J Radiol 9: 269-279, 2017.

18. Pinheiro C, Longatto-Filho A, Scapulatempo C, Ferreira L, Martins S, Pellerin L, Rodrigues M, Alves VA, Schmitt F and Baltazar F: Increased expression of monocarboxylate transporters 1,2, and 4 in colorectal carcinomas. Virchows Arch 452: $139-146,2008$

19. Lin JX, Xie XS, Weng XF, Qiu SL, Xie JW, Wang JB, Lu J, Chen QY, Cao LL, Lin M, et al: Overexpression of IC53d promotes the proliferation of gastric cancer cells by activating the AKT/GSK3 $\beta /$ cyclin D1 signaling pathway. Oncol Rep 41: 2739-2752, 2019.

20. Wang CJ, Zhou ZG, Holmqvist A, Zhang H, Li Y, Adell G and Sun XF: Survivin expression quantified by Image Pro-Plus compared with visual assessment. Appl Immunohistochem Mol Morphol 17: 530-535, 2009.

21. Knutsen A, Adell G and Sun XF: Survivin expression is an independent prognostic factor in rectal cancer patients with and without preoperative radiotherapy. Int J Radiat Oncol Biol Phys 60: 149-155, 2004

22. Livak KJ and Schmittgen TD: Analysis of relative gene expression data using real-time quantitative PCR and the 2(-Delta Delta C(T)) method. Methods 25: 402-408, 2001

23. National Research Council (US) Committee for the Update of the Guide for the Care and Use of Laboratory animals: Guide for the Care and Use of Laboratory Animals. 8th edition. National Academies Press, Washington, DC, 2011. Available from: https:// www.ncbi.nlm.nih.gov/books/NBK54050/

24. Rhodes DR, Ateeq B, Cao Q, Tomlins SA, Mehra R, Laxman B, Kalyana-Sundaram S, Lonigro RJ, Helgeson BE, Bhojani MS, et al: AGTR1 overexpression defines a subset of breast cancer and confers sensitivity to losartan, an AGTR1 antagonist. Proc Natl Acad Sci USA 106: 10284-10289, 2009.

25. Stewart DJ: Wnt signaling pathway in non-small cell lung cancer. J Natl Cancer Inst 106: djt356, 2014.

26. Xu K and Zhao YC: MEF2D/Wnt/ $\beta$-catenin pathway regulates the proliferation of gastric cancer cells and is regulated by microRNA-19. Tumour Biol 37: 9059-9069, 2016.

27. I H and Cho JY: Lung cancer biomarkers. Adv Clin Chem 72 : $107-170,2015$

28. Han G, Wei Z, Cui H, Zhang W, Wei X, Lu Z and Bai X: NUSAP1 gene silencing inhibits cell proliferation, migration and invasion through inhibiting DNMT1 gene expression in human colorecta cancer. Exp Cell Res 367: 216-221, 2018.

29. Wu X, Xu B, Yang C, Wang W, Zhong D, Zhao Z, He L, Hu Y, Jiang L, Li J, et al: Nucleolar and spindle associated protein 1 promotes the aggressiveness of astrocytoma by activating the Hedgehog signaling pathway. J Exp Clin Cancer Res 36: 127, 2017.

30. Gulzar ZG, McKenney JK and Brooks JD: Increased expression of NuSAP in recurrent prostate cancer is mediated by E2F1. Oncogene 32: 70-77, 2013.
31. Reichert N, Wurster S, Ulrich T, Schmitt K, Hauser S, Probst L, Götz R, Ceteci F, Moll R, Rapp U and Gaubatz S: Lin9, a subunit of the mammalian DREAM complex, is essential for embryonic development, for survival of adult mice, and for tumor suppression. Mol Cell Biol 30: 2896-2908, 2010.

32. Ma L, Liu J, Liu L, Duan G, Wang Q, Xu Y, Xia F, Shan J, Shen J, Yang Z, et al: Overexpression of the transcription factor MEF2D in hepatocellular carcinoma sustains malignant character by suppressing G2-M transition genes. Cancer Res 74: 1452-1462, 2014.

33. Zhu HX, Shi L, Zhang Y, Zhu YC, Bai CX, Wang XD and Zhou JB: Myocyte enhancer factor $2 \mathrm{D}$ provides a cross-talk between chronic inflammation and lung cancer. J Transl Med 15: 65, 2017.

34. Zhang R, Zhang Y and Li H: miR-1244/myocyte enhancer factor $2 \mathrm{D}$ regulatory loop contributes to the growth of lung carcinoma. DNA Cell Biol 34: 692-700, 2015.

35. Su L, Luo Y, Yang Z, Yang J, Yao C, Cheng F, Shan J, Chen J, Li F, Liu L, et al: MEF2D transduces microenvironment stimuli to ZEB1 to promote epithelial-mesenchymal transition and metastasis in colorectal cancer. Cancer Res 76: 5054-5067, 2016.

36. Chen L, Wei T, Si X, Wang Q, Li Y, Leng Y, Deng A, Chen J, Wang G, Zhu S and Kang J: Lysine acetyltransferase GCN5 potentiates the growth of non-small cell lung cancer via promotion of E2F1, Cyclin D1, and Cyclin E1 expression. J Biol Chem 288: 14510-14521, 2013.

37. Li K, Pan J, Wang J, Liu F and Wang L: MiR-665 regulates VSMCs proliferation via targeting FGF9 and MEF2D and modulating activities of Wnt/ $\beta$-catenin signaling. Am J Transl Res 9: 4402-4414, 2017

38. Shang S, Hua F and Hu ZW: The regulation of $\beta$-catenin activity and function in cancer: Therapeutic opportunities. Oncotarget 8: 33972-33989, 2017

39. Zhou P, Jiang W, Zhang YJ, Kahn SM, Schieren I, Santella RM and Weinstein IB: Antisense to cyclin D1 inhibits growth and reverses the transformed phenotype of human esophageal cancer cells. Oncogene 11: 571-580, 1995.

40. Jiang Q, He M, Ma MT, Wu HZ, Yu ZJ, Guan S, Jiang LY, Wang Y, Zheng DD, Jin F and Wei MJ: MicroRNA-148a inhibits breast cancer migration and invasion by directly targeting WNT-1. Oncol Rep 35: 1425-1432, 2016.

41. Yue X, Zhao Y, Xu Y, Zheng M, Feng Z and Hu W: Mutant p53 in cancer: Accumulation, gain-of-function, and therapy. J Mol Biol 429: 1595-1606, 2017.

42. Sankala H, Vaughan C, Wang J, Deb S and Graves PR: Upregulation of the mitochondrial transport protein, Tim50, by mutant p53 contributes to cell growth and chemoresistance. Arch Biochem Biophys 512: 52-60, 2011.

43. Muller PA, Trinidad AG, Timpson P, Morton JP, Zanivan S, van den Berghe PV, Nixon C, Karim SA, Caswell PT, Noll JE, et al: Mutant p53 enhances MET trafficking and signalling to drive cell scattering and invasion. Oncogene 32 : $1252-1265,2013$

44. Buganim Y, Kalo E, Brosh R, Besserglick H, Nachmany I, Rais Y, Stambolsky P, Tang X, Milyavsky M, Shats I, et al: Mutant p53 protects cells from 12-O-tetradecanoylphorbol-13acetate-induced death by attenuating activating transcription factor 3 induction. Cancer Res 66: 10750-10759, 2006.

This work is licensed under a Creative Commons Attribution-NonCommercial-NoDerivatives 4.0 International (CC BY-NC-ND 4.0) License. 